\title{
Twentieth Century Sociological Intimations, Twenty-First Century Contradictions: Neutralizing Racism and Reclaiming Whiteness
}

\author{
Jesus A. Garcia ${ }^{1}$
}

In the virtual echo chamber of $21^{\text {st }}$-century social media, the replacement of primary social bonds with virtual secondary bonds has led to violence and death in the real world. Due to ideological demagoguery and acceptance of violence in far-right-wing groups, imaginary realms in cyber-space have become sites from which terroristic acts flow into non-virtual life. Sociological theory from the past century predicts the current situation and fosters an understanding of how such technology leads to concentrations of racist ideologies and a reversal of Enlightenment values. Twentyfirst-century research suggests that those who commit race-driven violence against civil society perceive their actions as non-deviant and necessary. [Article copies available for a fee from The Transformative Studies Institute. E-mail address: journal@transformativestudies.org Website: http://www.transformativestudies.org (02022 by The Transformative Studies Institute. All rights reserved.]

KEYWORDS: Hegemony, Mass Media, Agents of Socialization, Ideology, Cyber-Racism, Violent Praxis.

\section{SOCIAL MEDIA AND VIRTUAL CULTURE}

Social media has established new relations between the individual and society. Classic sociological constructions of social structure and culture, however, are capable of still shining light into new social realities. The era of internet-mediated communications has normalized anti-social ideologies that inspire adherents of White Supremacy to put their beliefs into violent action in real life. The entangled relationship between structuring institutions' racial ideology and social violence is explored

\footnotetext{
${ }^{1}$ Jesus A. Garcia, Ph.D., earned his doctoral degree from Texas A\&M in Sociology with specializations in the study of Race/Ethnic Relations, Sociological Theory, and Cultural Studies. Research objectives have investigated cross border crime and deviance along the South Texas/Mexico border, Sociological Theory, Criminology, Race/Ethnic Relations, Sociology of Immigration, Critical Theory, Latino Sociology, and Modernity. In his spare time Dr. Garcia enjoys riding horses and dreaming of a brighter future for all.
} 